boiling solution of alkaline sodium picrate, the massive white constituent and the needles and bars were stained brown, thus proving them to be cementite (cf. Figs. 5 and 6 , which represent the same areas as Figs. 1 and 3). The duplex matrix was very lightly etched, which is consistent with the view that it is the eutectoid of ferrite and cementite, and the irregular white patches appeared to be segregated areas of this mixture. Constitutionally, therefore, this 'iron' is a high-carbon nickel-cobalt steel.

The microstructure of the metal is altogether different from what would be found in an alloy of this composition which had solidified from the liquid state, and the question arises as to how it has been formed. The following view is accordingly put forward. The metal, which may originally have been carbonless, has been heated to a temperature probably in the neighbourhood of $900^{\circ} \mathrm{C}$. in contact with carbon or more likely with carbon monoxide. This gas may have been produced by the combustion of lignite, beds of which occur on the island. Indeed it is possible that the metal has been produced from iron oxide which was first reduced by the gas to metallic iron and then carburised. The crystalline masses of cementite were formed in this way, but before the whole of the iron had been converted into the carbide, the temperature began to fall and the supply of carbon monoxide probably ceased, perhaps because of the exhaustion of the source of carbonaceous matter. At this point the alloy consisted of crystalline cementite and gamma iron saturated with carbon, that is, austenite containing more than 1 per cent carbon in solid solution. As the temperature fell, needles and bars of proeutectoid cementite crystallised from the austenite until the eutectoid temperature was reached, when the remaining austenite changed to the finely divided globular type of pearlite seen in the micrographs. The segregated areas may have been produced by slow coalescence of the cementite in the eutectoid during geological ages.

I wish to acknowledge the assistance of Mr. C. W. Dannatt and Dr. M. S. Fisher in this work.

\title{
Economics of Air Transport*
}

$\mathrm{T}$ HE report on the Economics of Air Transport in Europe, recently submitted by M. Henri Bouchée to the special sub-committee of the Air Transport Co-operation Committee of the League of Nations, appointed to study the constitution and operation of a main network of permanent air routes, affords a dismal picture of the frustration of science. The report shows clearly that such free competition as exists in Europe to-day is chiefly competition in paying out subsidies. The waste and inefficiency in aviation which result from this commercial aviation are difficult to parallel. In the three years $1930-32$, subsidies for aviation cost the European taxpayer about 2,000 million francs. Even in 1933, only four companies in Europe had advanced even half-way towards paying their way. At the end of 1932 British enterprises were nearly two thirds of the way, German enterprises only two fifths, French enterprises one fifth, Italian enterprises one fifteenth and air transport in Europe as a whole nearly one third.

In regard to actual use made of different air routes, the figures given in the report show the startling supremacy of the London-Paris air route, which in 1932 carried $5274 \mathrm{t}$. $\mathrm{km}$. per $\mathrm{km}$. of line, its nearest rivals being the Amsterdam-London route with 744 ton $\mathrm{km}$. and the Paris-Amsterdam with $623 \mathrm{t} . \mathrm{km}$. On certain routes, such as the Venice-Brindisi route, the figures are as low as $21 \mathrm{t}$. km., while financial returns indicate even more strikingly the supremacy of the London-Paris route, which shows more tonneskilometres utilised than the whole of the Belgian, Swiss, Czechoslovak, Polish, Swedish, Danish, Finnish, Austrian, Hungarian, Yugoslav and Roumanian services put together.

M. Bouchée points out that if the aircraft of Great Britain and of Finland carried a complete load, they would no longer need a subsidy, while the aircraft of the Netherlands would be independent if they were

* Economics of Air Transport. By Henri Bouchée. Alr Transport Co-operation Committee, League of Nations. (London: George Allen and Unwin Ltd., 1935). loaded to $\mathbf{7 5}$ per cent of their capacity. These figures prove that, from an economic point of view, certain lines are already operated very efficiently, and indicate that unsubsidised air transport in Europe is a matter of efficient technique and sound organisation. The obstacles to co-operation and efficiency are mainly political, and the relatively short distances flown in Europe will illustrate this point. 'They do not afford the decisive advantage which is possible in long. distance flights, and the system, as M. Bouchée remarks, is far more of the nature of propaganda than economic utility or the fulfilment of permanent needs. While surface traffic does not provide fast transport in Europe, the area is suitable for fast daytime flying, and that part of it which is most economically active will soon be a single territorial district which a fast aircraft will cross in half a day's day-time flying. The present services do little to meet the need for fast transport. Equally important is the question of giving air transport the freedom which is natural to it.

M. Bouchée calculates that, by rationalisation of European aviation, the whole of the present traffic could be carried with a quarter of the present European air fleet. Redundant or grossly uneconomic lines could be closed down and others at present non-existent could be set up. Air transport in Europe needs to be considered as a public utility service in the same way as the Postal Union or the International Sleeping Car Company, and the realities of the situation faced, so that aircraft no longer follow routes imposed on them or keep to Customs airports, 'corridors of approach' or 'prohibited zones'. The question, M. Bouchée concludes, is a political one. It cannot be solved merely by experts. Some form of internationalism is necessary if the present subsidies in Europe are to multiply direct and fast air services across territory better equipped and more freely accessible. In itself, the close co-operation essential might make a decisive contribution to the moral unity of Europe. 